REVISTA DE DERECHO UNED, NÚM. 11, 2012

\title{
POLÍTICAS DEL MULTICULTURALISMO, INMIGRACION Y DERECHOS DIFERENCIALES EN EL NUEVO CONTEXTO GLOBAL
}

\section{POLICIES OF THE MULTICULTURALISM, IMMIGRATION AND DIFFERENTIAL RIGHTS IN THE NEW GLOBAL CONTEXT}

\author{
Rafael Aguilera Portales \\ Profesor titular de Teoría Política y Jurídica de la Facultad \\ de Derecho y Criminología de la Universidad Autónoma \\ de Nuevo León, Monterrey (México)
}

En todos los hombres me veo, ninguno es más ni menos que yo, Y lo bueno y lo malo que digo que de mí, lo digo de los otros. Sé que soy sólido y fuerte,

Hacia mí convergen sin fin las incesantes cosas del universo, Todas me escriben y debo descifrar esas escrituras.

Walt Whitman, Hojas de hierba.

Recepción original: 24/07/2012

Aceptación original: 31/07/2012

\section{MULTICULTURALISMO Y MIGRACIÓN EN EL CONTEXTO GLOBAL}

El siglo XX y el presente siglo ha sido predominantemente «la era de las migraciones", "el siglo de los derechos de las minoras", "la era de los nacionalismos» por excelencia, un tiempo caracterizado principalmente por la afirmación creciente de las "políticas de la diferencia»o "políticas del multiculturalismo» ${ }^{1}$. Las sociedades de-

${ }^{1}$ Vid. KYMLICKA, W., Ciudadanía multicultural, Una teoría liberal de los derechos de las minorías, Paidós, Barcelona, 2000; DE LUCAS MARTÍN, J. ¿Qué quiere decir tener derecho a la cultura? en ABRAMOVICH, V., AÑON, M. J., COURTIS, Ch. (comp.) Derechos sociales, México, Fontamara, 2003, pp. 297-321, p. 303. Ver 
mocráticas modernas tienen que hacer frente cada vez más a grupos minoritarios, a flujos migratorios que exigen el reconocimiento de su identidad, sus patrones culturales y la integración de sus peculiaridades y diferencias culturales, algo que, a menudo, se denomina el reto del «multiculturalismo» ${ }^{2}$. Como afirma el gran sociólogo Sami Naîr: «esta globalización engendra la mutación de pertenencias, la desregulación de la identidades nacionales, la ausencia de un paradigma de referencia colectiva. De ahí el repliegue sobre los marcadores primarios: la identidad personal, la referencia confesional, la pertenencia étnica, la identidad lingüística diferenciada, ... ${ }^{3}$ Nuestras sociedades postmodernas, en breve tiempo, han pasado de las ruinas de las sociedades tradicionales a las sociedades modernas y postindustriales; pero a su vez, de las ruinas de las sociedades modernas están surgiendo dos procesos irreversibles: por un lado, el crecimiento de las redes globales de producción, consumo y comunicación y, por el otro, una especie de retorno a comunidades cerradas, compactas y homogéneas. En este sentido, el multiculturalismo y comunitarismo como corrientes político-jurídicas han realizado una defensa de la comunidad como sustrato de la socialización personal y social.

En el presente trabajo pretendo analizar una problemática difícil, ardua y compleja, a la que todavía no encontramos solución plena y convincente: la conciliación entre conceptos como integración y diferenciación sociocultural y jurídica, es decir cómo conciliar los

también otros trabajos interesantes DE LUCAS MARTÍN, J., La inmigración, por Derecho, Editorial Tirant lo Blanch, Valencia, 2004. BOTEY, VALLÉS, J., «Continuidad y ruptura en el cruce de culturas» en Actas del Congreso Internacional de Salamanca, "Desafíos actuales en la comunicación intercultural», Noviembre 2002.

2 En la actualidad hay 184 Estados independientes en el mundo, se hablan más de 600 grupos de lenguas vivas y hay unas 5.000 culturas societarias. Lo cual significa que, salvo casos excepcionales como Islandia y las dos Coreas (que son países culturalmente muy homogéneos), la inmensa mayoría de los Estados actuales son multiculturales y plurilingües. En América Latina hay más de 40 millones de indígenas. En Bolivia, Guatemala, Honduras, Perú y Ecuador más del 80\% de la población es indígena, México es el país con mayor cantidad de indígenas: 12 millones. Actualmente existe una amplia corriente multicultural de defensa de los derechos diferenciales de las culturas minoritarias y el deseo de prevenir su absorción o fagocitación por parte de la cultura dominante y mayoritaria de un determinado Estado. La humanidad no es una tabula rasa, hoy por hoy, la diversidad es un a priori de la realidad mundial, un dato que está ahí cuando llega la globalización y sobre el cual ésta se organiza. El mundo no sólo es plural, sino «incorregiblemente plural», como recientemente nos ha recordado Jean y John Comaroff. Especialmente, Vasconcelos reivindicó y defendió la cultura y el mestizaje iberoamericano como elemento constitutivo y esencial de la cultura hispanoamericana.

3 SAMI NAÎR, "Los inmigrantes y el Islam europeo», Claves de la Razón práctica, Madrid, n. ${ }^{\circ} 105$, septiembre, 2000, p. 8. 
derechos fundamentales, iguales para todos los ciudadanos, con los derechos diferenciales peculiares y característicos de ciertas minorías étnicas, culturales, sociales y políticas. En primer lugar, porque nos encontramos en un enorme Estado multiétnico y multicultural como México ${ }^{4}$, donde numerosas minorías diferenciales reclaman un reconocimiento no sólo cultural sino también jurídico-político. No obstante, conviene precisar que nos hallamos ante una problemática no sólo local, sino global que requiere de una solución urgente debido no sólo a la mayor movilización geográfica, económica y migratoria sino también por los profundos cambios que se están avecinando y experimentando en la actualidad en el anquilosado y viejo Estado-nación ${ }^{5}$, un estado moderno que no sabe dar respuesta certera todavía al problema de la globalización.

Una sociedad es multicultural en un sentido sociológico y demográfico si contiene altos niveles de diversidad étnica y racial, esta diversidad cultural puede proceder originariamente de minorías étnicas y raciales ya existentes en un determinado Estado o procedente de los nuevos procesos migratorios que se están produciendo a escala internacional. Tradicionalmente, el Estado democrático de derecho se enfrenta a la problemática de cómo hacer frente a la diversidad cultural para procurar unos mínimos comunes de convivencia política; pero el desafío actual va más allá del reconocimiento del pluralismo político e ideológico que caracteriza cualquier democracia moderna. A menudo, la convivencia social compuesta de heterogeneidad y diversidad de individuos, creencias, costumbres, valores, relaciones entre las distintas comunidades constituye una fuente de desencuentros, tensiones y conflictos. Incluso dentro de un mismo Estado-nación coexisten diversidad de culturas, con lo cual

${ }^{4}$ El sociólogo francés Alain Tourine nos expone: «En primer lugar aprendimos a pensar nuestras historia en términos políticos, luego la interpretamos a la luz de la economía y las relaciones sociales de producción. Ahora, en un nuevo contexto internacional tenemos que analizarla y construirla en términos culturales. Los elementos antagónicos ya no son un rey y un pueblo o capitalistas y trabajadores, sino un información globalizada e identidades comunitarias definidas en términos más culturales que económicos o sociales.» TOURINE, A., ¿podremos vivir juntos? México, FCE, p. 58; Vid. KUNG, H., Proyecto de una ética mundial, Trotta, Madrid, 1998; VILLORO, L., Estado plural. Diversidad de culturas, México, Paidós, 1998.

${ }^{5}$ Maquiavelo, en el siglo XV, contempló la fragmentación y la debilidad de los Estados italianos y apostó por su fortalecimiento y conservación como garantía segura frente al caos, la guerra y la inseguridad. Indudablemente, las amenazas son otras; pero volvemos a asistir a una desintegración de los Estados modernos, por diferente causa. Entonces se constituían los Estados-nación, hoy comienza su crisis crónica, tal vez, irreversible especialmente en algunos países África, América y Asia. ARAMAYO Roberto-VILLACAÑAS, J. L. (comp.), La herencia de Maquiavelo (modernidad y voluntad de poder), México, Fondo de Cultura Económica, 1999. 
nos encontramos con el problema de la multiculturalidad no sólo a nivel global, sino también nacional o local.

La globalización tecnológica y cultural ${ }^{6}$ ha realizado un hecho prodigioso jamás alcanzado en nuestra historia. Nuestro planeta se empequeñece, vivimos en una aldea global electrónica ${ }^{7}$ debido a la facilidad de las comunicaciones y el acortamiento de distancias físicas y geográficas; pero también es cierto que en todas partes se fortalecen y multiplican los agrupamientos comunitarios, los nacionalismos, los fundamentalismos, las asociaciones fundadas en una pertenencia común, las sectas, los cultos, los fundamentalismos y que las sociedades vuelven a convertirse en comunidades homogéneas. Nos encontramos ante una realidad socio-política en la que cuando estamos todos juntos, no tenemos casi nada en común, y cuando compartimos unas creencias y una historia, rechazamos a quienes son diferentes de nosotros.

Por consiguiente, el dilema actual que se nos plantea es ¿cómo podremos vivir juntos si nuestro mundo está dividido en al menos dos continentes cada vez más alejados entre sí? Por un lado, observamos, comunidades que se defienden contra la penetración de individuos, ideas, costumbres provenientes del exterior desde la afirmación de la cultura propia y, por otro lado, aquel cuya globalización tiene como contrapartida un influjo fuerte y arrasador sobre conductas personales y colectivas que diluye y homogeneiza la identidad cultural.

El final del siglo XX e inicio del siglo XXI está marcado por choques entre culturas ${ }^{8}$ cuya dimensión es muy considerable y aprecia-

${ }^{6}$ A. MCGREW, "Globalization and Territorial Democracy», en A. McGraw (comp.), The Transformation of Democracy?, Cambridge, 1997, IANNI, Octavio, La sociedad global, siglo XXI, México, 1995, 3. ${ }^{\circ}$ edición. NORBERT, Elías, La sociedad de los individuos, (trad. Cast. José Antonio Alemany), Barcelona, Ediciones Península, 1990; MARTINELLO, M., «Inmigración y construcción europea: ¿Hacia una ciudadanía multicultural en la Unión Europea?», trad. de M. Unceta, en Lamo de Espinosa, E. (ed.), Culturas, Estados, Ciudadanos, Alianza, Madrid, 1995; FARIÑAS, M. J., Globalización, ciudadanía y derechos humanos, Cuadernos Bartolomé de las Casas, Dykinson, Madrid, 2000; THIEBAUT, C., «Cosmopolitismo y pertenencia», Laguna, número extraordinario, 1999, pp. 101-119.

${ }^{7} \mathrm{El}$ concepto proviene de la reflexión sociológica de la comunicación de MARSHALL MACLUHAN. Una nueva forma de organización social tiende a expandirse por todo el planeta transformándose en una nueva ciudad: telépolis, la aldea global electrónica. Las naciones y los Estados dejan de ser formas determinantes de la vida social y se forma progresivamente una aldea global gracias a las comunicaciones donde todos los ciudadanos del mundo se interrelacionan e interactúan a distancia, directa e indirectamente. MARSHALL MACLUHAM, Hebert, The global village, Oxford University Press, Canada, 1989.

8 «La colonización española creó mestizaje, esto señala su carácter, fija su res- 
ble. En cada uno de los cinco continentes se están dando continuas migraciones intercontinentales, movilizaciones y desplazamientos de población hacia las grandes ciudades. En nuestro continente de América latina, cientos de miles de personas se han visto obligadas durante los últimos años a abandonar sus campos para establecerse en los suburbios de la megaurbes o metrópolis, pensemos sólo en el fuerte y creciente flujo migratorio hacia nuestro país vecino, EEUU donde se calcula que viven aproximadamente cerca de 35 millones de latinoamericanos: los refugiados se cuentan por millones en la India, Pakistán, Bangladesh China Indochina, Corea, Camboya, Vietnam, Afganistán, Irak, Líbano; las gentes huyen despavoridas y sin futuro en la región africana de los Grandes Lagos y siguen sin encontrar su hogar en oriente medio, la antigua Yugoslavia, en algunas de las repúblicas de la antigua URSS o en Turquía. El número de inmigrantes procedentes de países empobrecidos de América del Sur, África, Asia, y Este de Europa crece sin cesar en toda la Europa occidental y EEUU. Basta recordar los conflictos de irlandeses, belgas, vascos, escoceses, Kurdos, armenios, albano-kosovares, libaneses afganos, palestinos, et. La situación mundial actual demuestra que el nacionalismo es una de las concepciones políticas del mundo más duraderas y sólidas de la modernidad. El refugiado, el excluido y paria ocupan hoy en el mundo el lugar que ocupo el antiguo proletariado en el interior de los estados europeos industrializados. Los desplazamientos masivos de población y choque entre culturas han caracterizado casi siempre la historia por la reaparición de la barbarie e intolerancia ${ }^{9}$.

Normalmente, en las sociedades donde rige el mestizaje y el multiculturalismo, se suele olvidar, por lo general, la trágica historia de los conflictos que casi siempre ha acompañado a la trasculturalización, a la integración de las culturas invadidas por las culturas agresoras y el asimilacionismo de las culturas de la inmigración por la cultura mayoritaria del país de destino. En nuestros países sigue

ponsabilidad y define su porvenir. El inglés siguió cruzándose sólo con el blanco, y exterminó al indígena, lo sigue exterminando en la sorda y callada lucha económica, más eficaz que la conquista armada». $C f r$. VASCONCELOS, José, La raza cósmica, Espasa-Calpe, México, 2003, p. 19. Figuras como Alfonso Reyes, José Vasconcelos, Octavio Paz, Calos Fuentes ilustran de forma clara y contundente una defensa explicita de esta multiculturalidad como expresión de encuentro y dialogo abierto y permanente entre todas las culturas, especialmente en la cultura iberoamericana.

${ }^{9}$ GONZÁLEZ JIMÉNEZ, Manuel, «El problema de la tolerancia en la España de las tres culturas», en BADILLO O'FARRELL (coord.) Pluralismo, tolerancia, multiculturalismo, Universidad Internacional de Andalucía, Madrid, Akal, 2003, pp. 125-141; FERNÁNDEZ BUEY, F., «Barbarie, tolerancia, igualdad en la diversidad» en CRUZ Manuel (comp.) Tolerancia o barbarie, Barcelona, Gedisa, 1998, pp.103-140. 
rigiendo un fuerte etnocentrismo ${ }^{10}$ que nos lleva frecuentemente hacia actitudes de rechazo, discriminación, xenofobia y racismo.

La inmigración y la incorporación de minorías étnicas y raciales son las dos fuentes más comunes de diversidad cultural en los Estados modernos. Estas dos experiencias sociológicas hacen necesario diseñar y formular nuevas políticas multiculturales que propicien una mejor integración socio-cultural y socio-económica.

\section{MULTICULTURALISMO EN EL ESTADO DEMOCRÁTICO Y SOCIAL DE DERECHO}

Las sociedades democráticas modernas tienen que hacer frente cada vez a grupos minoritarios que exigen el reconocimiento de su identidad y sus diferencias culturales. La multiculturalidad es una expresión nítida y clara del hecho social e histórico del pluralismo cultural, de la existencia de códigos culturales distintos en nuestras sociedades democráticas. Kymlicka es un autor preocupado por los problemas de las minorías dentro de sociedades complejas multiculturales, como ocurre en Canadá, y en este sentido ha elaborado

${ }^{10}$ Este retorno a la comunidad, ya anunciado por Tönnies a fines del siglo XIX, trae consigo el llamado a la homogeneidad, la pureza, la unidad, y la comunicación es reemplazada por la guerra entre quienes ofrecen sacrificios a dioses diferentes. El etnocentrismo descansa en una actitud psicológica antigua, que aparece en nosotros ante una situación inesperada de encuentro con otras culturas, consiste en repudiar las formas culturales que son diferentes, extrañas y alejadas de nosotros por otras más cercanas y comunes con las cuales nos identificamos plenamente. El etnocentrismo consiste en la actitud que sobrevalora nuestra cultura propia e infravalora la ajena, la distinta, la diferente. Para ampliar sobre esta temática puede consultarse AGUILERA, PORTALES, R., «El problema del etnocentrismo en el debate antropológico entre Clifford Geertz, Richard Rorty y Lévi-Strauss», en Gaceta de Antropología, Universidad de Granada, n. ${ }^{\circ} 18,2002$, pp. En este trabajo expongo una interesante discusión entre el antropólogo Clifford Geertz y Richard Rorty, junto con LéviStrauss, sobre el problema de la interculturalidad. Estos defienden un etnocentrismo débil y moderado que nos aleje de todo universalismo vacío, abstracto y caduco, mientras Geertz critica fuertemente el relativismo cultural en el que incurren. Esta discusión se enmarca dentro de un debate de mayor envergadura entre postilustrados y postmodernos. "La herofobia no es un sentimiento humano sino humanísimo -dice Savater- ya que favorece una cierta cohesión social y refuerza la identificación con el propio grupo». SAVATER, F. Diccionario filosófico, Barcelona, planeta, 1996, p. 159, voz "heterofobia», ver también "De las culturas a la civilización», Claves de la razón práctica, septiembre, 2000, n. ${ }^{\circ}$ 105, pp. 5-11. Los griegos hablaban de «bárbaro» a todo el que fuese extranjero, mientras que nuestra civilización occidental utilizó el término "salvaje». GEERTZ, Clifford, Los usos de la diversidad. Barcelona, Paidós, 1996, TODOROV, Tzvetan, Nosotros y otros. México, Siglo XXI, 1991. Ver también su trabajo Cruce de culturas y mestizaje cultural, Madrid, Júcar, 1988. 
«una Teoría liberal de derechos colectivos» ${ }^{11}$. Desde esta perspectiva, Kymlicka se acerca a posiciones comunitaristas cuando concibe a los seres humanos no como "átomos aislados» sino como sujetos sociales y comunitarios cuya pertenencia a un grupo cultural constituye un ingrediente esencial de sentido y autoestima como individuos. La tradición liberal, según Kymlicka, ha sostenido una neutralidad estatal frente a grupos etnoculturales, de forma, que cualquier forma de ciudadanía diferenciada puede ser peligrosa por la primacía de un determinado grupo sobre el individuo. El liberalismo político se ha equivocado al no dar importancia a la pertenencia a un grupo cultural como factor decisivo de bienestar individual y del propio respeto.

En su libro Ciudadanía multicultural Kymlicka distingue tres modelos de Estado ante el fenómeno emergente de la diversidad cultural: los «Estados nacionales» cuyos modelos paradigmáticos pueden ser Francia, Inglaterra y Alemania ; los Estados «multinacionales» ${ }^{12}$, como Reino Unido, Suiza, España, Bélgica, Unión Europea que surgen de la incorporación de culturas minoritarias que en algún momento de su historia han disfrutado o disfrutan de alguna forma de autogobierno, en estos Estados varias minorías nacionales, con su lenguas propias e instituciones separadas coexisten junto a la cultura societaria dominante. Por tanto, en estos Estados una o más minorías nacionales, con sus lenguas propias e instituciones separadas coexisten junto a la cultura societaria dominante; los «Estados multiétnicos o poliétnicos», como Estados Unidos, Canadá, México como fruto de la inmigración individual y grupal y la diferencias de colectivos tradicionalmente desfavorecidos en el seno de cualquier Estado.

${ }^{11}$ KYMLICKA ha trabajado el problema debido a la complejidad del proceso de integración-diferenciación en su propio país, Canadá. El concepto de «ciudadanía compleja» tiene algún parentesco con el de «igualdad compleja» utilizado por Michael Walter (1983) y es un concepto que desborda ampliamente el concepto de «ciudadanía multicultural» de Kymlicka (1995); DE LUCAS, J., «Introducción. El vínculo social, entre ciudadanía y cosmopolitismo", AA. VV., en El vínculo social: ciudadanía y cosmopolitismo, Tirant lo Blanch, Valencia, 2002, pp. 11-27.

${ }^{12}$ Estados multietnicos (Estados Unidos, Canadá, México y cada vez más Francia, Alemania, ect.) y Estados multinacionales (Reino Unido, España, Bélgica y la futura Unión Europea). KYMLICKA, Will, «Derechos individuales y derechos de grupo en la democracia liberal» en Revista Isegoría (Revista de Filosofía moral y política), Madrid, CSIC, n. ${ }^{\circ}$ 14, 1996, pp. 5-37, p. 14. Véase también MARTINELLO, M., «Inmigración y construcción europea: ¿Hacia una ciudadanía multicultural en la Unión Europea?», trad. de M. Unceta, en Lamo de Espinosa, E. (ed.), Culturas, Estados, Ciudadanos, Alianza, Madrid, 1995; FERNÁNDEZ BUEY, F., «Barbarie, tolerancia, igualdad en la diversidad» en CRUZ, Manuel (comp.) Tolerancia o barbarie, Barcelona, Gedisa, 1998, pp. 103-140. 
Will Kymlicka ha defendido un multiculturalismo integrador donde reivindica tres formas de derechos colectivos diferenciados ante la insuficiencia de la simple defensa de los derechos individuales para resolver adecuadamente el problema de la diversidad cultural dentro de la concepción de Estado democrático de derecho ${ }^{13}$. Los derechos a los que se refiere son los derechos de autogobierno (exigencia de algún tipo de autonomía política), los derechos poliétnicos (exigencia de respeto a la herencia étnica, formas de expresión, lenguaje, respeto de sus prácticas religiosas siempre que esta diferencia no obstaculice su éxito en las instituciones económicas y políticas de la sociedad dominante), estos derechos protegen ciertas prácticas religiosas, sociales y culturales específicas que no han sido reconocidas por la legislación vigente. Pensemos por ejemplo en las reivindicaciones de determinadas minorías en relación con su lengua, todos conocemos la importancia de la lengua como factor cultural constitutivo y decisivo de la personalidad humana y de un determinado grupo etnocultural. La lengua constituye un fenómeno social y político ampliamente extendido y ligado a la reivindicación de los derechos culturales de ciertas naciones y grupos étnicos. El caso de Québec, Cataluña, País vasco, cantones belgas es significativo y sintomático en este aspecto $^{14}$.

Y los derechos especiales de representación ${ }^{15}$ que consisten en la exigencia de representación de los grupos diversos o diferentes, porque existen desventajas sistemáticas que impiden su afirmación

${ }^{13}$ La actual concepción político-jurídica de «Estado social y democrático de Derecho» ha superado el carácter netamente formal del tradicional Estado de Derecho tratando de dotarlo de una dimensión social, pluralista y solidaria. Igualmente, conseguimos integrar los contenidos materiales que proporciona la sociedad, mediante el derecho de participación democrática, sometido al principio de legalidad y al marco competencial constitucionalmente establecido, consiguiendo cerrar el círculo del Estado social y democrático de Derecho. Vid. DÍAZ, Elías, Estado de Derecho y Sociedad Democrática. Cuadernos para el diálogo, Madrid, 1969. GONZÁLEZ MORENO, B., El Estado social, Naturaleza Jurídica y estructura de los derechos sociales, Madrid, Civitas, 2002, p. 44. Véase también PISARELLO, Gerardo, "Los derechos sociales en el constitucionalismo democrático» en Boletín Mexicano de Derecho Comparado, n. ${ }^{\circ}$ 92, México, UNAM, 2006; AGUILERA PORTALES, Rafael, «Fundamento, naturaleza y garantías jurídicas de los derechos sociales ante la crisis del Estado social» en Revista Telemática de Filosofía del Derecho, Madrid, n. ${ }^{\circ}$ 10, año 2006, pp. 1-29.

${ }^{14}$ Cfr. LÓPEZ CALERA, N., ¿Hay derechos colectivos? Individualidad y socialidad en la teoría de los derechos, Ariel, Barcelona, 2000, p. 28; DE LUCAS, J., Europa: ¿convivir con la diferencia? Racismo, nacionalismo y derechos de las minorías, TecnosFundación Enrique Luño Peña, Madrid, 1992.

${ }^{15}$ KYMLICKA, W., Ciudadanía multicultural, op. cit..., pp. 46-55. 
como grupo étnico y su identidad. La representación política dentro de las instituciones políticas del conjunto de la sociedad hace menos probable que una minoría nacional o étnica sea ignorada en decisiones que afectan globalmente al país. Normalmente, la representación política de estos grupos minoritarios suele ser filtrada a través de los grandes partidos políticos; pero la lógica política de estas organizaciones no suele considerar a estas minorías, por lo estos grupos no suelen tener voz ni voto en las congresos o parlamentos, salvo que se constituyan ellos mismos en grupo político, pero esto suele ser inusual debido a su marginalidad. La falta y carencia de integración política, económica y social que tienen los pueblos indígenas sigue siendo una asignatura pendiente en muchos Estados. Si alcanzamos ciertos de derechos especiales de representación de estos amplios sectores de población podemos conseguir desarrollar y alcanzar un modelo de ciudadanía inclusiva y multicultural en el seno del Estado democrático.

Los derechos poliétnicos y especiales de representación política pueden fomentar la integración social y política, mientras que los derechos de autogobierno, representan un desafío más serio e importante a la integración de la ciudadanía en un determinado Estado Federal ${ }^{16}$. La mayor parte de los derechos poliétnicos dan por supuesta la autoridad de los organismos políticos del conjunto de la sociedad, asumiendo que los inmigrantes trabajan dentro de una institución económica y política general.

En concreto, en el caso de los pueblos indígenas ${ }^{17}$ en muchos casos no ha existido una aspiración a convertirse en naciones-Estado, en primer lugar, porque se les excluyó y discriminó en el proceso de construcción nacional y estatal y, en segundo lugar, porque no lo consideraron viable y positivo dentro del propio proceso cultural e institucional. No obstante, esta marginación histórica no elude la aspiración legítima como minorías nacionales del derecho a conservar y mantener su cultura societal como cultura distintiva y diferencial en el seno del Estado-nación.

${ }^{16}$ Véase para ampliar sobre el tema mi trabajo sobre federalismo AGUILERA PORTALES, Rafael Enrique, «La encrucijada de una ciudadanía constitucional europea a través del pensamiento federalista» en TORRES ESTRADA, Pedro y BARCELO ROJAS, Daniel (ed.) La Reforma del Estado, Editorial Porrúa, México, 2007; FERRANDO BADÍA, J., EL Estado unitario, el federal y el Estado regional, Madrid, 1978.

${ }^{17}$ IBARRA PALAFOX, F., Multiculturalismo e instituciones politico-constitucionales, México, Ed. Porrúa, 2007; DE BLAS GUERRERO, A., Nacionalismo e ideologías políticas contemporáneas, Espasa-Calpe, Madrid, 1984. 


\section{POLÍTICAS DEL MULTICULTURALISMO Y DERECHOS DE LAS MINORÍAS}

Sin embargo, en muchos Estados democráticos occidentales han abandonado históricamente las actitudes de rechazo y políticas públicas de asimilación. La nueva perspectiva del multiculturalismo ha hecho que se hayan ido incrementando un amplio espectro de políticas multiculturales no sólo hacia las comunidades indígenas, sino para los inmigrantes, el reconocimiento de los derechos lingüísticos de las minorías nacionales, así como el reconocimiento de ciertas formas de autogobierno y derechos territoriales. La nuevas políticas del reconocimiento de la ciudadanía exigen un cambio de perspectiva en torno al análisis y reconocimiento de estos grupos etno-culturales diferenciales.

\section{III.1. Políticas multiculturales hacia los inmigrantes: ¿ciudadanos o indocumentados?}

En el pasado, sabemos que ha existido una tendencia asimilacionalista de los grupos de inmigrantes; pero esta política pública y estatal está siendo modificada por una visión de política multicultural e intercultural ${ }^{18}$. La política asimilacionalista consistía en que los inmigrantes fueran cambiando sus hábitos de vida, culturas, costumbres, vestimentas, lengua, por la sociedad recepcionista o mayoritaria preexistente. No obstante desde finales de los años sesenta, hemos presenciado cambios importantes con respecto a esta visión claramente etnocentrista y reduccionista. Hasta 1960 los inmigrantes que iban a Estados Unidos, Canadá y Australia se les exigían que asimilasen la cultura y las normas culturales existentes del país de recepción. De hecho a muchos inmigrantes se les denegaba la en-

${ }^{18}$ El auténtico diálogo intercultural no es una posición de mero sincretismo, es decir, limitarse a yuxtaponer elementos distintos de culturas diferentes de un modo ecléctico arbitrario e indiferente. La posición intercultural requiere de un enorme esfuerzo de comunicación, diálogo, comprensión y encuentro. El diálogo no es una posición de debilidad y claudicación, sino de fuerza, prestancia y creatividad. RUBIO CARRACEDO, J. L., Retos pendientes en Ética y política Revista Malacitana, n. 5. Véase también el estudio de THIBAUT. C., Los límites de la comunidad, Centro de Estudios Constitucionales, Madrid. Isaiah BERLIN ha definido el pluralismo como la existencia de una variedad de ideas, una multiplicidad de objetivos humanos y una multiplicidad de valores, no siempre y no todos ellos conmensurables y a veces hasta en definitiva oposición entre sí. Para el estudio del pensamiento de Berlin ver ESCÁMEZ NAVAS, Sebastián, «La razón ocultó la cara del pluralismo del pensar político» en VOLUBILIS (Revista de pensamiento U.N.E.D.), Melilla, n. ${ }^{\circ} 12$, pp. 90-102. 
trada si no eran conformes a dicha política cultural del estado. La asimilación era considerada óptima para la estabilidad y seguridad de la homogeneidad de un estado. En un primer momento, se adoptó la perspectiva neutral ${ }^{19}$ en términos raciales, de forma que los inmigrantes pudieran ser tratados de forma igualitaria con respecto a los nativos de origen, pero sin expresar su identidad cultural, en un segundo momento, se adoptó la política multicultural de la integración de la inmigración a partir de la cual la cultura receptora espera que los inmigrantes expresen, visible y orgullosamente su cultura de origen y se espera que las instituciones públicas ( policía, escuelas, hospitales, medios de comunicación...) puedan acomodarse a estas identidades étnicas no sólo a través de su reconocimiento sino su protección, promoción y desarrollo. En este segundo momento, se considero que la política asimilacionista había fracasado en la integración de estos nuevos ciudadanos, por lo que era necesario cambiarla hacia un política más plural y tolerante donde eran respectados los derechos a la propia cultura del inmigrante en cuanto a viajas costumbres, comidas, vestido, religión, ocio.. así como la posibilidad y el derecho de reunión y asociación para ejercer estas prácticas culturales.

La inmigración consiste en abandonar voluntariamente su propia cultura con la expectativa de integrase en otra sociedad nacional. Normalmente, la inmigración constituye un fenómeno individual o familiar, no suelen emigrar comunidades enteras o poblaciones, por ello, los inmigrantes carecen de la concentración territorial o de las instituciones que puedan representarlos en los países de destino o recepción. Esto les da una desventaja que tienen que superar y supone un esfuerzo de adaptación lingüística, cultural, política y social. Los inmigrantes suelen aceptar el uso de una lengua común, puesto que decidieron dejar su propia cultura y adoptar una nueva, para las sociedades o minorías nacionales la imposición de una determinada lengua mayoritaria constituye un atentado o amenaza a su propia cultura. Los inmigrantes luchan por integrarse puesto que su motivación suele ser generalmente económica, más que política o cultural.

La inmigración suele despertar una imagen negativa, prejuiciosa y xenófoba en los países de recepción considerada en términos de amenaza externa para los ciudadanos nacionales de origen, como

${ }^{19}$ Vid. AGUILERA PORTALES, Rafael Enrique, «El problema del etnocentrismo en el debate antropológico entre Clifford Geertz, Richard Rorty y Lévi-Strauss», en Gaceta de Antropología, Universidad de Granada, 2002, n. ${ }^{\circ} 18$, pp. 35-65. 
si una avalancha de gente que quiere entrar en nuestros países, aun cuando no se necesitan dichos individuos. Aunque esta visión negativa, como dice Javier de Lucas está siendo superada por una visión de política pragmática en clave instrumental laboral (los necesitamos para mantener las pensiones y el sistema de seguridad social) o vienen a realizar trabajos que los nacionales no queremos.. y otra en clave paternalista o asistencialista de un humanitarismo que no comprende suficientemente el fenómeno. La política de inmigración entonces se adapta a las necesidades el mercado laboral de dichos individuos. Y pone énfasis al mismo tiempo en la lucha contra la inmigración ilegal. Javier de Lucas denomina a esta doble tensión o dimensión de la política de inmigración el dilema cornudo o bien pragmatismo cínico laboral o bien paternalismo asistencial de caridad que suele ser la política que la UE y España aplica en la actualidad.

Will Kymlicka y Keith BANTING proponen la adopción de ocho políticas públicas ${ }^{20}$ para la integración y reconocimiento de la inmigración como formas comunes de política multicultural.

1. Aprobación constitucional, legislativa o parlamentaria del multiculturalismo, a nivel central, regional y municipal.

2. La adopción del multiculturalismo en el curriculum escolar.

3. La inclusión de la representación-sensibilidad étnica en el mandato de los medios de comunicación públicos, o en las licencias o permisos de los medios de comunicación privados.

4. La dispensa en códigos culturales de vestir, comidas, legislación sobre el cierre de ciertos días, ect..

5. El reconocimiento de la doble ciudadanía.

6. El financiamiento de las organizaciones culturales de los grupos étnicos.

7. El financiamiento de la educación bilingüe o de la instrucción en la lengua materna.

8. La acción afirmativa para los grupos de inmigrantes en desventaja.

Las políticas de acción positiva pretenden incrementar el número de inmigrantes que participan en las instituciones del país garantizándoles una porción de cargos en diversas instituciones académicas, económicas o políticas. Otra política interesante para avanzar en el reconocimiento de este tipo de ciudadanía consiste en la incorporación en los curriculums de este fenómeno que viene a

${ }^{20}$ BANTING, Keith y KYMLICKA, Will, ¿Qué son las políticas multiculturales?» En derechos de minorías y estado de bienestar, México, Universidad Nacional Autónoma de México, 2007, p. 28. 
contribuir y desarrollar el propio estado. Igualmente, los gobiernos centrales y locales deben apoyar e impulsar el surgimiento de medios de comunicación sociales que ayuden a fomentar una mayor sensibilidad étnica y tolerancia multicultural. El reconocimiento de la doble ciudadanía ayuda a la incorporación de los inmigrantes en una nueva sociedad. El papel de los medios de comunicación como voceros y portavoces de las exigencias y reivindicaciones de estos ciudadanos es decisivo y fundamental. Las contribuciones históricas de estos grupos sociales suelen ser notables y beneficiosas para el país del origen.

\section{III.2. Políticas multiculturales hacia los pueblos indígenas: la ciudadanía multicultural}

En un pasado, casi todos los países adoptaron políticas cuyo objetivo principal consistía en la desaparición de comunidades indígenas o la asimilación de las mismas por la cultura mayoritaria del Estado. En este sentido, los pueblos indígenas fueron despojados de sus tierras naturales, se restringió la práctica de su cultura, lengua y religión tradicionales, y se debilitó notablemente sus instituciones de autogobierno e impartición de justicia. En este sentido, se ha ido produciendo un cambio o giro copernicano en la formulación de dichas políticas públicas. Se ha ido aceptando la idea de que los pueblos indígenas van a existir en un futuro como sociedades distintas y específicas en el seno de un determinado Estado, con ciertos derechos territoriales, culturales y de autogobierno como derechos colectivos específicos y necesarios para su integración real y efectiva.

En este sentido, Will Kymlicka y Keith BANTING proponen nueve políticas como aproximación a un tratamiento político y jurídico de reconocimiento e integración de estas comunidades naturales:

1. Reconocimiento de derechos y títulos territoriales.

2. Reconocimiento de derechos de autogobierno.

3. Defensa histórica de tratados y suscripción de nuevos tratados.

4. Reconocimiento de derechos culturales (lenguaje, caza-pesca).

5. Reconocimiento del derecho consuetudinario.

6. Garantía de representación-consulta en el gobierno central.

7. Declaración constitucional o legislativa en el gobierno central.

8. Apoyo y ramificación de los instrumentos internacionales sobre derechos indígenas.

9. Acción afirmativa. 


\section{III.3. Políticas multiculturales hacia minorías nacionales signifi- cativas}

Actualmente, estamos viviendo un nuevo resurgir de los nacionalismos $^{21}$ junto a políticas de reconocimiento por parte del Estado de ciertas minorías culturales. Históricamente, estas minorías étnicas y culturales han sido discriminadas y subsumidas por una cultura societaria mayoritaria, normalmente, bajo el modelo a veces impositivo del Estado liberal. El derecho a mantener una diferencia cultural dentro de la homogeneidad es un derecho fundamental de todo grupo etnocultural particular como derecho a preservar su propia cultura. Pero, tenemos que puntualizar que el derecho a preservar la identidad cultural de un determinado grupo es de naturaleza distinta de la pretensión de a la autodeterminación de un grupo. Estos derechos no son equiparables ${ }^{22}$. El derecho a la autodeterminación de los pueblos no es un derecho incondicional, incontrovertible y absoluto. El derecho a preservar la identidad cultural, étnica, religiosa y lingüística del grupo no significa que exista un derecho correlativo a constituirse como Estado-nación.

En la mayoría de los Estados-nación existe un grupo dominante que organiza la vida en común, refleja su historia y su propia cultura a través de la educación pública, los símbolos y las ceremonias de la vida pública. Por tanto, el estado no es neutral respecto a las historias y las culturas, el aparato del estado se encarga de la reproducción nacional, sin embargo, puede tolerar a las minorías nacionales como la mayoría de los estados liberales y democráticos hace.

Michael Walzer critica la falsa y supuesta neutralidad cultural del estado-nación cuando pretende imponer una cultura nacional dominante en oposición a las minoritarias. Las minorías nacionales constituyen grupos que suelen tener mayores probabilidades de encontrase en peligro.

${ }^{21}$ HABERMAS, J., La constelación postnacional (trad. Cast. Pere Fabra Abat, prólogo Camps, V.), Paidós, Barcelona, 2000. Al respecto también se puede consultar para ampliar sobre la problemática del nacionalismo AGUILERA PORTALES, Rafael Enrique, «Multiculturalismo, Federalismo y derechos culturales» en Teoría política y jurídica contemporánea (Problemas actuales), México, Editorial Porrúa, 2008.

${ }^{22}$ NÚÑEZ LADEVÉZE, Luis, «Derechos de los pueblos y derechos humanos» en Revista de Estudios Políticos, Centro de Estudios Políticos y Constitucionales, Madrid, n. ${ }^{\circ}$ 125, julio/septiembre 2004, pp. 227-255; DE LUCAS, J., El desafió de las fronteras. Derechos humanos y xenofobia frente a una sociedad plural, Temas de hoy, Madrid, 1994. 
Michael Walzer ha definido muy certeramente el comportamiento de un Estado-nación frente a ciertas minorías nacionales.

«El Estado reclama poseer derechos jurisdiccionales exclusivos, y considera a todos los ciudadanos como individuos, en lugar de como a miembros de distintos grupos. De ahí que los objetos de la tolerancia, estrictamente hablando, sean las elecciones y las realizaciones individuales: actos de adhesión, de participación en rituales de pertenencia y de culto, representaciones de la diferencia cultural, ect... Se anima a los hombres y a las mujeres individuales a mostrase tolerancia mutua en tanto que individuos, entendiéndose en cada caso que la diferencia es una versión personalizada (en vez de un estereotipo) de la cultura del grupo- lo que también significa que los miembros de cada grupo, si han de poder manifestar la virtud de la tolerancia, han de aceptar las distintas versiones del otro. Todo el mundo tiene que tolerar a todo el mundo. No se permite que ningún grupo se organice con fines coercitivos, que se haga con el control del espacio público o que monopolice los recursos públicos. En principio, las escuelas públicas enseñan la historia y el civismo del Estado, que es concebido de forma que no se tenga una identidad nacional, sino una identidad política. La historia y la cultural de las diferentes grupos no se enseña en absoluto, y si se enseña, como sucede desde hace poco en los Estados Unidos (y en algunos otros lugares), se hace en dosis iguales, de forma multicultural.» ${ }^{23}$

El Federalismo en la actualidad despierta un gran interés entre los estudiosos de diversas áreas como la Ciencia Política, la Administración Pública, el Derecho, la Economía, la Sociología política y la Teoría y Filosofía Política. Esta concepción institucional de Estado presenta una enorme fascinación, atractivo y prestigio a nivel mun-

${ }^{23}$ WALZER, Michael, La política de la diferencia, p. 91. Estados Unidos fue uno de los laboratorios iniciales del Federalismo que más curiosidad y atractivo suscitaron a los intelectuales europeos, uno de esos viajeros fue Alexis de Tocqueville. Estados Unidos era una nación incipiente, una especie de «Europa inacabada»con sus conflictos y defectos. Otro viajero que cruzó el Atlántico fue Max Weber realizando una intensísima experiencia geográfica e intelectual. TOQUEVILLE, Alexis, La democracia en América, Madrid, Aguilar, 2 vols., 1989; BAUMAN, Zygmunt, Europa. Una aventura inacabada (trad. J. Etorena), Madrid, Losada, 2006; OFFE, Claus, Autorretrato a distancia (trad. Álvarez-Mayo), Buenos Aires, Katz Editores, 2006. El federalismo no sólo es una creación de los artífices de la Constitución estadounidense de 1787, sino que encontramos claros precedentes filosóficos en pensadores como Althusio, Abad Saint-Pierre, Montesquieu, Kant o Rousseau, Goethe, Jovellanos, Saint-Simon, Charles Lemonnier, Toqueville, Proudhon, Auguste Comte, Giuseppe Mazzini, Victor Hugo, Krause y autores más recientes contemporáneos como Albert Camus, Denis de Rougemont, Edgard Morin entre muchos más; pero no pretendo hacer una historia del pensamiento Federalista, sino reseñar ciertos logros, conquistas y fracasos en la configuración y búsqueda del Estado Constitucional. 
dial. En primer lugar, podemos señalar que el federalismo se caracteriza por ser una técnica y método fundamental de organización jurídico-política, es decir, un método vivo que actúa para ajustar progresivamente las instituciones políticas existentes, sus competencias y funciones dentro del conglomerado del Estado Constitucional; pero, sobre todo, el federalismo es un pensamiento, una actitud ante los demás y la sociedad, una concepción política, jurídica y metafísica de toda sociedad democrática, tolerante y plural. Por tanto, podemos extraer y aprender del federalismo no sólo técnicas jurídicas sino, también, y lo más importante una serie de valores, principios y una cultura político-jurídica que carecemos desgraciadamente en la actualidad.

Sin duda, la estructura jurídico-política del Estado unitario ${ }^{24}$ emergió inicialmente para dar respuesta a las necesidades históricas de superar las estructuras sociales y políticas del feudalismo en el Medioevo, las monarquías absolutas en Europa protagonizaron el proceso de concentración de poder político, que alumbró los primeros Estados modernos. Sin embargo, el federalismo como aplicación del principio de distribución democrática del poder es incompatible con la autocracia que encarna la concentración del poder. La condición humana tiende siempre al abuso, los gobiernos se deslizan con cierta facilidad hacia el despotismo y la tiranía «que causa a la naturaleza humana males espantosos» como afirma Montesquieu.

«Esas leyes fundamentales suponen necesariamente ciertos canales intermedios por donde fluye el poder, pues si en el Estado no hubiera más que la voluntad momentánea y caprichosa de uno sólo, nada podría tener fijeza y, por consiguiente, no habría ninguna ley fundamental. $»^{25}$

De aquí, que la principal amenaza para la libertad y la democracia provenga de la creciente concentración de poder en manos del Estado. Por el contrario, el federalismo pretende la distribución del poder entre distintos órdenes jurídicos y sociales (Federación,

${ }^{24}$ El profesor Prélot describe como el Estado simple o unitario es aquel que posee un único centro de impulsión política y un conjunto único de instituciones de gobierno, por tanto, nos encontramos ante una forma política del poder unitaria en su estructura, en sus límites territoriales y elementos humanos. Véase PRÉLOT, M., Institutions politiques et Droit constitutionnel, París, 1972, también puede consultarse FERNÁNDEZ MIRANDA, F. y GONZALO, M., «Formas territoriales de Estado» en TORRES DEL MORAL, A., Derecho Político, Universidad Nacional de Educación a Distancia, Madrid, 1988, pp. 347-358; FERRANDO BADÍA, J., El Estado unitario, el federal y el Estado regional, Madrid, 1978.

${ }^{25}$ MONTESQUIEU, De l'esprit des lois, (trad. de Merceces Blázquez y Pedro de Vega, prólogo de Tierno Galván Del espiritu de las leyes, Madrid, Tecnos, 1972, p. 36. 
estados, municipios), y, en este sentido, entiende que la democracia implica poliarquía, es decir, una distribución del poder entre los diversos órganos del Estado y, a su vez, una distribución de poder entre los Estados miembros federativos. El desarrollo de la autonomía Federativa y municipal ${ }^{26}$ y la correspondiente descentralización político-administrativa del poder estatal es el fundamento de una cultura política democrática y un desarrollo sustentable. La centralización gubernamental y administrativa es la causa del debilitamiento de las libertades locales y, por consiguiente, constituyen un verdadero peligro de despotismo estatal para cualquier sociedad democrática. Denis de Rougemont ha defendido que el espíritu del Federalismo ${ }^{27}$ no es posible sin el ejercicio de las virtudes republicanas ${ }^{28}$ ampliamente definidas y desarrolladas por Montesquieu en el $L^{\prime}$ Esprit des lois. Desde esta perspectiva, podemos concebir el federalismo como un «laboratorio de experimentación» dinámico, creativo, que «concibe la Constitución como una sistema abierto a la experimentación y la imaginación jurídico-políticas y (al poco explotado) pluralismo de configuración político-constitucional de las entidades federativa (dentro del marco de la Constitución federal) [...]» ${ }^{29}$

En una entrevista a Arnaldo Otegui -líder y responsable de Euskal Herritarok- el brazo político de la organización terrorista ETA proclamaba que los vascos son «el último pueblo indígena de Europa» y proclamaba el peligro de extinción de la raza y la cultura vasca y su derecho inexorable de autodeterminación política. Indudablemente, la apelación al recurso de la identidad étnica y cultural, junto a la pureza racial ha sido utilizada históricamente para defender intereses nacionalistas. Pensamos, por ejemplo, en el genocidio nazi

${ }^{26}$ TORRES ESTRADA, Pedro, La autonomía municipal y su garantía constitucional directa de protección, UNAM, México, 2005.

${ }^{27}$ DE ROUGEMONT, Denis, Tres milenios de Europa, Revista de Occidente, Madrid, 1963; DE ROUGEMONT, Denis, Amor y occidente, Consejo Nacional de Fomento Educativo, México, 1993.

${ }^{28}$ La concepción tradicional de virtud, dentro de la formación escolástica heredada, es un concepto fundamental en el cual se articulan la ética individual, social y política. Estas tres esferas no están separadas en compartimentos estancos sino que forman una unidad armónica en cuanto sostienen la concepción del hombre en la búsqueda del bien personal y colectivo. Véase IGLESIAS, Carmen, «Monstesquieu: ética y política» en Razón y sentimiento en el siglo XVIII, Madrid, Real Academia de la Historia, 2001, $2 .^{\circ}$ edición, pp. 147-215, p. 151. GINER, Salvador, "Cultura republicana y política del porvenir» en GINER, S., ARBÓS X., y otros La cultura de la democracia: el futuro, Barcelona, Ariel, 2000, 137-172, p. 137.

${ }^{29}$ BRAGE CAMACHO, Joaquín, Estudio preliminar a HÄBERLE, Peter, El federalismo y el regionalismo como forma estructural del Estado Constitucional, México, UNAM, pp. 25-130, p. 39. 
de millones de judíos, gitanos, deficientes psíquicos, gays, ect., apelando a la pureza racial y la conservación de una cultura alemania aria. Por eso, identificar ciudadanía nacional con identidad étnica y racional puede ser una política peligrosa y perversa, que nos ayude a excluir y perseguir a otros grupos étnicos. En este sentido, debemos separar el status de ciudadanía de cualquier componente étnica o racial; sobre todo si vivimos en sociedades multituculturales y poliétnicas donde el mestizaje étnico y racial está plenamente extendido. Por consiguiente, debemos alejar la noción de ciudadanía de cualquier intento de política de identidad.

En esta línea las propuestas de adopción de políticas multiculturales $^{30}$ que Keith BANTING, y Will Kymlicka formulan son:

1. Autonomía territorial federal o cuasifederal.

2. Estatuto lingüístico oficial, ya sea en la regional o nacionalmente Garantía de representación en el gobierno central o la Corte Constitucional.

3. Garantía de representación en el gobierno central o en la $<$ corte constitucional.

4. Financiamiento público de la lengua de las minorías, de sus universidades-escuelas-medios de comunicación.

5. Declaración constitucional o parlamentaria del multiculturalismo.

6. Reconocimiento de la personalidad internacional por ejemplo, permitir que la región subestatal tenga un asiento en los organismos internacionales, o firme tratados o posea su propio equipo olímpico.

En este sentido, el Federalismo se basa en el principio de compaginar unidad con diversidad, un poder central coexistente con una pluralidad de poderes federativos, es decir, la renuncia a toda forma de hegemonía, despotismo o absolutismo burocrático de nuevo cuño. El federalismo se basa en el amor a la complejidad: es lo contrario a la simplificación totalitaria, homogeneización funcional o la uniformidad impuesta por el poder central. ${ }^{31}$ El Federalismo es expresión y reivindicación de un constitucionalismo democrático que refleja claramente la Constitución del pluralismo, en el ámbito local estatal federativo, en ámbito nacional (Federación) y, en el

${ }^{30}$ BANTING, Keith y KYMLICKA, Will, «¿Qué son las políticas multiculturales?» En derechos de minorías y estado de bienestar, México, Universidad Nacional Autónoma de México, 2007, p. 34.

${ }^{31}$ SIDJANSKI, Dusan, El futuro Federalista de Europa (prólogo de José María GilRobes Gil-Delgado), Barcelona, Ariel, 1998, p. 220. 
ámbito internacional, con la apertura de los Estados constitucionales hacia una comunidad internacional federativa que erradique el actual desorden internacional. En realidad, la federación sólo puede nacer, crecer y desarrollarse en un espacio de libertad, democracia y pluralismo con multiplicidad de ideas, culturas, partidos, regiones, y en el contexto de creación constante de un tejido social complejo y diversificado.

\section{DEBATE POSTMODERNO ENTRE RELATIVISMO O UNIVER- SALISMO DE LOS DERECHOS HUMANOS}

El problema fundamental hoy es que la cultura, como dice la profesora Victoria Camps, los valores culturales sin más, no se miden de hecho, desde patrones éticos, sino desde cánones de la cultura de masas, que es la cultura de los países ricos y desarrollados, de las sociedades industriales orientadas al crecimiento desmedido, ilimitado y arrasador. Nuestros universales hoy en día no son los de la ética o los derechos humanos. El problema ético y jurídico de la diversidad cultural ha de ser confrontado con la tesis de la homogeneidad cultural, una cultura compartida por todos, que significa modernización y progreso.

El problema de la interculturalidad, las diferencias culturales y ataque de la universalidad de los derechos humanos tiene su centro de gravedad en la polémica o debate contemporáneo ${ }^{32}$ entre pensadores modernos o postilustrados y postmodernos. La versión postmoderna de este debate se debe quizás a Jean Francois Lyotard. El disenso, la activación de las diferencias, los islotes culturales sin comunicación mutua y la diversidad cultural son los elementos definidores de la actual situación. Las ideas de diálogo o comunicación intercultural pertenecen al universo y discurso moderno de las que deberíamos desprendernos. Según Lyotard no existe metalenguaje (Habermas) ${ }^{33}$, ni ningún consenso superpuesto (Ralws), ni ningún

${ }^{32}$ LYOTARD, Jean-Francois, La condición postmoderna. Madrid. Cátedra, 1984. El debate o polémica entre las corrientes comunitaristas y liberales lo protagonizan los liberales como J. Habermas, J. Rawls, R. Dworkin, K.O. Popper, frente a los comunitaristas como Charles Taylor, Michael Walzer, A. MacIntyre, M. Sandel, Richard Rorty, Benjamín Barber. Para ampliar sobre este tema puede consultarse mi trabajo AGUILERA PORTALES, Rafael «Entre la ética y la política: debate contemporáneo entre liberales y comunitaristas» en VALDÉS MENOCAL, C. y SÁNCHEZ BENÍTEZ, Roberto, Ética, Política y Cultura desde Cuba publicado en Universidad Michoacana de San Nicolás de Hidalgo (México) y Universidad de la Habana (Cuba), 2005, pp. 69-85

${ }^{33}$ HABERMAS, J., Teoría de la acción comunicativa. Taurus, Madrid, 1983. 
mínimo común denominador entre las diversas culturas (Michael Walzer $)^{34}$.

Ante esta situación surgen muchos interrogantes como ¿es la homogeneizacion tan negativa como creemos? ¿a quién no le gustaría que el respeto a los derechos humanos no fuera más homogéneo?, por ejemplo, ¿son las diferencias culturales siempre buenas, legítimas y dignas de respeto? ¿Cómo podemos conservar la diversidad cultural sin que esto no disminuya la capacidad de encuentro intercultural?

Sin duda, el mundo está perdiendo diversidad cultural. Los procesos de globalización tecnológica han favorecido a la implantación de una monocultura a escala planetaria. Hannerz lo demuestra que en última instancia la cultura se genera y articula siempre sobre la base de experiencias personales que se producen en el ámbito de lo local, y como la localidad y familiaridad siempre está ganando la partida a lo global y extraño, pues lo global sólo puede penetrar en lo local si se reduce a algo familiar y comprensible. La polémica entre la homogenización y la diversidad cultural, entre quienes afirman, por un lado que el mundo se macdonaliza (homogeneización cultural) y los que por el contrario aseguran una balcanización y fragmentación galopante (relativismo cultural) constituye una polémica banal que debemos superar. "Las personas pueden parecerse en algunos aspectos y ser diferentes en otros, y lo que hace falta en el ecúmene global es más bien un estudio teórico de dos cosas que ocurren a la vez: la apertura y la variación» ${ }^{35}$.

Los padres de la antropología contemporánea comenzaron hablando de lo global y lo local, insistiendo en la doble naturaleza del

${ }^{34}$ Michael WALZER postula una «igualdad compleja», que conduce a una «justicia compleja» ${ }^{12}$. Pero ello puede conducir, no ya al pluralismo social, sino al relativismo generalizado, si no se adoptan cautelas para que se mantenga, al menos, una justicia mínima, generalmente compartida. La "justicia en las esferas» no se opone sino que más bien supone, una teoría de la justicia básica. Mientras los pensadores liberales inciden, de forma especial, en los procedimientos, los comunitaristas inciden en los bienes compartidos que alimentan la justicia. WALZER, M. Esferas de la justicia, México, F.C.E., 1993. MILLER, D. y WALZER, M., (comps), Pluralismo, justicia e igualdad, México, F. C. E. Walzer, Michael, Interpretation and Social Criticism, Cambridge (Massachusets), Harvard University Press.

${ }^{35}$ HANNERZ, Conexiones transnacionales. cultura, personas, lugares, Cátedra, Madrid, 1998, p.59 Para Hannerz, la homogenización y la diversidad no dependen tanto de la realidad como de los modelos como pensamos la realidad de lo que hannerz llama metaculturas. Hay dos metaculturas dominantes, una que permite ver y tratar el mundo como homogéneo y otra que permite verlo y tratarlo como diverso. Más que preocuparse por cuál de las dos ofrece la visión correcta de la realidad, Hannerz propone una combinación de perspectivas y de objetivos. 
concepto de cultura: por un lado, lo universal que nos une a todos y, por otro, el conjunto de peculiaridades específicas que nos separa (la cultura de los esquimales, los mexicas, tarahumaras...) Lo paradójico es que si bien todos los antropólogos suscriben en la teoría la dualidad de acepciones, en la práctica solo tienen dos alternativas: o insistir en lo común de la cultura humana o insistir en la diversidad de las culturas humanas. En la primera opción, Insistir en la multiplicidad de las culturas incomoda no solo conceptual, sino también éticamente, porque los acerca a la posición de relativismo cultural.

Estos pensadores cuestionan y ponen en entredicho la pretendida universalidad moral y jurídica ${ }^{36}$ al afirmar que los derechos humanos, formulados en las normas internacionales vigentes, han surgido de una tradición liberal occidental y constituyen un instrumento de dominación e imperialismo cultural occidental dentro del actual orden político internacional.

En esta última década, se vienen produciendo distintas Declaraciones y Conferencias recientes de países africanos y asiáticos (Túnez en 1992, Bangkok en 1993, o la Conferencia Islámica del mismo año). Estas Conferencias sin dejar de admitir la universalidad de los derechos de la Declaración, la contextualizar en las tradiciones y valores culturales de cada pueblo, lo que en la Declaración de El Cairo de 1990 suscrita por 51 Estados había significado que los derechos humanos se reconocen sólo en cuanto sometidos a la ley islámica. La universalidad de los derechos se subordinaba así a una particularidad religiosa.

Desde posiciones contextualistas o multiculturales extremas, muchos gobiernos de África y Asia apoyados por un gran sector de filósofos, antropólogos y juristas contemporáneos responden que la universalidad de los derechos humanos es en realidad una imposición cultural europea, un producto eurocentrista. De este modo, la Declaración ${ }^{37}$ encubriría un etnocentrismo occidental (eurocentris-

${ }^{36}$ Se trataría de que las culturas formen o lleguen a formar una comunidad democrática social cosmopolita. Este espacio ecúmeno global consistiría en facilitar encuentros libres y abiertos de todas las culturas, para crear una sociedad universal. En este sentido podemos acudir a Richard Rorty quien defiende la necesidad de narrativas de un cosmopolitismo mayor, aunque no narrativas de emancipación, porque piensa que no hay nada de lo que emanciparse. Hay que desechar la retórica revolucionaria de la emancipación y del desenmascaramiento, en favor de la retórica reformista e institucional a favor de una mayor tolerancia y un menor sufrimiento. RORTY, Richard, "Intelectuals in politics», Dissent. Autum, 1991, Batallas éticas (con T. Abraham y A. Badiou). Buenos Aires, Nueva Visión; Pragmatismo y política. Barcelona, Paidós, 1998.

${ }^{37}$ RUBIO CARRACEDO, J. L., «Globalización y diferencialidad de los derechos 
mo cultural), vestigio cultural, político y económico del imperialismo colonial occidental del siglo pasado.

Los derechos humanos precisan de mayor clarificación y dilucidación conceptual, dentro del proceso irreversible e imparable de globalización. Por tanto, nos encontramos ante dos tendencias opuestas, universalidad y diferencialidad de los derechos humanos, que nos están sometiendo a todo tipo de dilemas, desafíos y contradicciones que debemos afrontar. Como señala el profesor Truyol y Serra: «La conciencia clara y universal de los derechos humanos es moderna; es en la modernidad cuando a la conciencia universalista de dignidad, una vez hecho el recorrido desde los medievales «derechos estamentales» hasta los «derechos del hombre», se añade la reivindicación de la protección jurídico-política de los derechos que a dicha dignidad corresponden». ${ }^{38}$

Sin duda, la experiencia horrenda, bárbara y brutal del holocausto ${ }^{39}$ ha marcado un punto de inflexión en torno a nuestra propia visión histórica y tradición occidental. Estos acontecimientos históricos determinan una voluntad política occidental decidida y firme a favor de la prevención, protección y expansión de los derechos humanos $^{40}$. De esta forma, la Declaración universal de la ONU en 1948 ha significado un replanteamiento de los fundamentos de los

humanos» en Revista ALFA (Asociación Andaluza de Filosofía), año IV, n. ${ }^{\circ}$ 8, 2000, pp. 69-91; CAMPS, V., "La universalidad ética y sus enemigos», en Universalidad y diferencia, (eds. S. Giner y R. Scartezzini). Alianza, Madrid, 1996.

${ }^{38}$ TRUYOL Y SERRA, Antonio, Los derechos humanos, Madrid, Tecnos, 1984, p. 12; ARA PINILLA, Ignacio, Las transformaciones de los Derechos Humanos, Tecnos, Madrid, 1990. PEREZ LUÑO. Antonio. Derechos humanos, Estado de Derecho y Constitución, Madrid, Tecnos, 1990; BÖCKENFÓRDE, Ernst Wolfang, Estudios sobre el Estado de Derecho y la democracia, (prologo de Rafael Agapito Serrano), Trotta, Madrid, 2000.

${ }^{39}$ Vid. GLOVER, Jonathan, Humanidad e inhumanidad. Una historia moral del siglo XX, trad. Marco Aurelio Galmarini, Madrid, Cátedra, 2001; GRAY, John, Perros de paja, Barcelona, Paidós, 2000; POPPER, K.O., En busca de un mundo mejor, Barcelona, Paidós, 1994. Cuando contemplamos los nefastos acontecimientos de Auschwitz, los Gulags o Hiroschima podemos corroborar el poco o nulo avance que hemos realizado en materia de derechos humanos en nuestro siglo pasado y actual. Estos acontecimientos nos deberían interpelar a realizar un mayor esfuerzo teórico y práctico de defensa, difusión y propagación de los derechos humanos. Entre 1492 y 1990, hubo al menos 36 genocidios que se cobraron, cada uno de ellos, entre decenas de miles y decenas de millones de vidas. Desde 1950, ha habido casi veinte genocidios; de ellos, al menos tres tuvieron más de un millón de víctimas (Bangladesh, Camboya y Ruanda). Sólo las dos guerras mundiales (1914 y 1945) se cobraron 55 millones de vidas humanas.

${ }^{40}$ DE LUCAS, J., Derechos de las minorías en una sociedad multicultural, Consejo General del Poder Judicial, Madrid, 1999. 
derechos humanos y la puesta en marcha un programa de universalización efectiva.

En la actualidad se ha alcanzado un consenso normativo internacional respecto a los derechos humanos, acontecimiento que representa una sólida defensa de un cierto universalismo relativamente fuerte frente a un relativismo cultural en sentido débil. La Declaración Universal de los Derechos Humanos representa una respuesta mínima de convergencia de valores humanos interculturales frente a las amenazas especiales que conllevan las instituciones modernas. En este sentido, La Declaración Universal de 1948 no se limitó sólo a fundamentar los derechos humanos en una lógica estrictamente iusnaturalista, sino que también comenzó a utilizar la categoría de consenso global como referente fundancional de los mismos. Una globalización jurídica como consecuencia necesaria de la globalización económica y cultural Como dice el profesor Xavier Etxeberria: «[...] un mínimo de «iusnaturalismo deontológico», un mínimo ideal de valores que gire en torno a la «esencial» dignidad de la persona humana es imprescindible como revulsivo permanente y universal contra toda legalidad y todo poder negador de la misma.» ${ }^{41}$

\section{EL DERECHO COLECTIVO A LA PROPIA CULTURA COMO DERECHO DIFERENCIAL}

En estas tres formas de diversidad cultural existe un denominador común que consiste en el derecho que posee cada comunidad a su propia cultura. Will Kymlicka nos habla de "cultura societal» como la cultura que proporciona a sus miembros unas formas de vida significativa a través de un abanico amplio de actividades humanas, incluyendo la vida social, educativa, religiosa, recreativa y económica que abarca tanto la esfera pública y la privada. La participación en este tipo de cultura proporciona acceso e integración social y ciudadana. El tipo de solidaridad esencial para un Estado de bienestar exige que los ciudadanos tengan un fuerte sentimiento de identidad y pertenencia común, de manera que se sacrificaran unos por otros, y para que esto suceda se debe tener una lengua e historia en común. Dada las presiones a favor de la creación de una única cultura en común de cada país, para que una cultura pueda sobrevivir y se desarrolle en un mundo moderno debe ser una cul-

${ }^{41}$ ETXEBARRIA, Xavier, «Universalismo ético y derechos humanos» en RUBIO CARRACEDO, J. L. Retos pendientes en Ética y politica Revista Malacitana, n. ${ }^{\circ}$, Málaga, 2002. 
tura societal, y si esto no ocurre esta cultura se verá reducida a una marginación aún mayor.

En sentido genérico, el derecho a la propia cultura ${ }^{42}$ hace referencia explícita a la necesidad de preservar los elementos distintivos de la identidad de un pueblo o civilización a la cual se pertenece como sistema de creencias, valores, costumbres y conductas compartidas que son trasmitidas normalmente de generación en generación. Ciertas prácticas culturales exigen el reconocimiento de derechos por parte del Estado, por ejemplo, ciertas festividades, normas laborales y educativas; pero cuando aludimos al derecho a la propia cultura tratamos de resaltar una visión de la cultura no excluyente, ni pura, sino configurado e integradora en gran medida de la identidad de un determinado grupo social donde diferentes personas pertenecen. Desde esta perspectiva, cada cultura es polifacética, mestiza y polifónica y en su interior existe una rica pluralidad de visiones.

El derecho a la propia cultura consistiría, pues, en el derecho a preservar una determinada identidad cultural con sus señas de identificación, como costumbres, festividades, vestimenta, usos, normas especiales de educación, etc. La dimensión social y comunitaria del derecho a la cultura dificulta su caracterización como derecho subjetivo e individual, según el modelo reductivo de los derechos en la tradición liberal occidental. Una gran mayoría de pensadores sostiene que la idea de derechos colectivos o de grupo es incompatible con la tradición liberal. Según estos autores, la actitud del Estado liberal frente a los grupos etnoculturales debería ser una posición de neutralidad. Un Estado neutral no debería apoyar ni fortalecer la pertenencia a grupos etnoculturales, sino tratar de asegurar que sus ciudadanos no son objeto de discriminación racial, étnica o política, es decir, defender el reparto igual de los derechos individuales a todos los ciudadanos. En este sentido, Michael Walter, por ejemplo, mantiene que el liberalismo implica un «claro divorcio entre Estado y etnicidad». Sin embargo, esta supuesta neutralidad etnocultural del Estado liberal es un mito y una falacia, pues el Estado-

${ }^{42}$ Como señala especialmente el profesor Javier De Lucas bajo la fórmula aparentemente clara «derecho a la cultura» se incluyen derechos muy heterogéneos. El punto de partida es reconocer que el derecho a la cultura sería uno de los contenidos de los derechos culturales, pero no el único, es decir, que no cabe identificar derecho a la cultura y derechos culturales: junto al derecho a la cultura, entendido como derecho al propio patrimonio y herencia cultural, los derechos culturales incluirían, el derecho al acceso a la cultura, el derecho a la participación en la vida cultural y a su disfrute, o los derechos de protección de las creaciones científicas y artísticas (culturales). Véase el excelente trabajo de MARCOS DEL CANO, A. M., «Inmigración y el derecho a la propia cultura» en MIRAUT MARTÍN, L. (Ed.), Justicia, migración y derecho, Editorial Dykinson, Madrid, 2004, pp. 91-111. 
nación promueve una determinada "cultura societaria», es decir, un determinado conjunto de tradiciones, costumbres, convenciones, incluso una determinada lengua. Un ejemplo claro de este tipo de integración sociopolítica lo podemos ver en nuestro vecino Estados Unidos que siendo un país multicultural ha promovido una determinada cultura societaria, es decir, una determinada lengua, cultura, símbolos, tradiciones...Esta supuesta neutralidad que preconizan los Estados Unidos respecto a al diversidad de grupos etnoculturales es engañosa y falaz, pues el gobierno norteamericano promueve una determinada lengua, cultura e historia política concreta y exige a todos los inmigrantes que quieran adquirir la ciudadanía estadounidense el dominio de la lengua inglesa, el conocimiento de su historia y sus tradiciones. Incluso, la corte suprema de los Estados Unidos ha respaldado esta posición política del gobierno apoyando leyes que hacen obligatoria la enseñanza y el uso del inglés en las escuelas y la función pública. Paradójicamente, la constitución norteamericana no reconoce una lengua oficial del estado, ni unas costumbres o tradiciones, pero en la práctica el gobierno norteamericano exige esta «cultura societaria angloamericana» para adquirir derechos de ciudadanía. Por tanto, la supuesta neutralidad étnica y cultural que defiende los Estados liberales constituye una falacia y un engaño en la práctica de estos Estados.

Un aspecto de especial relevancia y significación del derecho a la propia cultura es el derecho a la propia lengua, particularmente decisivo en el caso específico de las minorías lingüísticas en el seno de un Estado democrático de derecho. El Convenio sobre pueblos indígenas y tribales en países independientes en su artículo 5 establece: «deberán reconocerse y protegerse los valores y prácticas sociales, culturales, religiosas y espirituales propios de dichos pueblos y deberá tomarse debidamente en consideración la índole de los problemas que se les plantean tanto colectiva como individualmente ${ }^{43}$.

El problema no es la igualdad de derechos sino el derecho a la diferencia dentro de la homogeneidad cultural mayoritaria dentro de una sociedad. El problema que se nos plantea, por tanto, es ¿cómo hacer viable ese derecho en una sociedad multicultural?, ¿cómo compaginar la diversidad cultural con un ordenamiento jurídico común que reconozca y contemple estas diferencias? En definitiva ¿cómo conciliar estos derechos colectivos y diferenciales con una cierta cohesión política y jurídica en el marco de un Estado nacional?

${ }^{43}$ El Convenio sobre pueblos indígenas y tribales en países independientes Adoptado el 27 de junio de 1989 por la Conferencia General de la Organización Internacional del Trabajo. Vinculación a México 5 de septiembre de 1990. 
En América Latina se pone de manifiesto como existe una fuerte confrontación o disfunción entre las legislaciones nacionales y las prácticas culturales en el caso de muchos pueblos indígenas aún no reconocidos plenamente. En las últimas décadas, las Constituciones políticas de los diversos Estados Americanos han tratado de reconocer la enorme diversidad de estos pueblos dentro del marco del Estado nacional; pero pese a su reconocimiento formal y legal todavía faltan políticas culturales de integración efectivas. ${ }^{44}$

Indudablemente, el reconocimiento que realizan las Constituciones Políticas latinoamericanas del derecho a la propio cultura es un elemento de especial relevancia para la protección y reconocimiento de los derechos humanos de los pueblos indígenas como el derecho a la autodeterminación en ciertos asuntos propios e internos; pero es urgente iniciar y facilitar otras formas y prácticas de integración político-jurídica, participación democrática y, sobre todo, integración socio-económica debido a su larga marginación histórica. ${ }^{45}$

El artículo 27 del Pacto Internacional de los Derechos civiles y Políticos expone: «En los Estados en que existan minorías étnicas, religiosas o lingüísticas, no se negará a las personas que pertenezcan a dichas minorías el derecho que les corresponde, en común con los demás miembros de su grupo, a tener su propia vida cultural, a profesar y practicar su propia religión y a emplear su propio idioma». Y el art. 2.1. del Pacto Internacional expresa: «Cada uno de los Estados Partes en el presente Pacto se compromete a respetar y a garantizar a todos los individuos que se encuentren en su territorio y estén su-

${ }^{44}$ La Constitución Política de los Estados Unidos Mexicanos proclama en el art. 2: «La Nación Mexicana es única e indivisible. La Nación tiene una composición pluricultural sustentada originalmente en sus pueblos indígenas que son aquellos que descienden de poblaciones que habitaban en el territorio actual del país al iniciarse la colonización y que conservan sus propias instituciones sociales, económicas, culturales y políticas, o parte de ellas». Constitución Política de los Estados Unidos Mexicanos, México, DOF 5/2/1917, última reforma aplicada DOF 29/10/2003. Igualmente, la Constitución española de 1978 en su artículo 44.1. declara: «Los poderes públicos promoverán y tutelarán el acceso a la cultura al que todos tienen derecho» Aunque el artículo 46 incluye un reconocimiento también al derecho al patrimonio cultural que puede dar pie a una interpretación favorable al reconocimiento de la identidad cultural, «Los poderes públicos garantizarán la conservación y promoverán el enriquecimiento del patrimonio histórico, cultural, artístico de los pueblos de España». Cfr. PÉREZ LUÑO, E. Derechos humanos. Estado de derecho. Constitución, 1999, 6. ${ }^{\circ}$ ed., pp. 494 y ss.

${ }^{45}$ BURGUETE, Cal y Mayor, RUIZ HERNÁDEZ, M., «Hacia un Carta Universal de los Derechos de los Pueblos Indígenas», Vid. Derechos Indígenas en la Actualidad, IIJ-UNAM, México, 1994. 
jetos a su jurisdicción los derechos reconocidos en el presente Pacto, sin distinción alguna de raza, color, sexo, idioma, religión, opinión política o de otra índole, origen nacional o social, posición económica, nacimiento o cualquier otra condición social». ${ }^{46}$

Pero, conviene detenernos a precisar y aclarar el concepto de cultura para eludir posibles equívocos y confusiones y poder desarrollar, posteriormente, con propiedad del derecho a la cultura como un derecho fundamental. Por el término cultura podemos señalar dos usos de la palabra: uno, muy genérico y amplio, que entendien de cultura como "perfeccionamiento en virtud del cual el hombre se humaniza». Esta concepción está presente en la paideia griega y la humanitas latina.

La palabra cultura ${ }^{47}$ deriva del verbo latino colere que significa cultivar. Una forma de este verbo es cultum que en latín significa agricultura. El adjetivo cultus ser refiere a la propiedad que tiene un campo de estar cultivado. Originariamente pues, cultura quería decir cultivado, agricultura y con el tiempo comenzó a compararse al espíritu de una persona ruda con un campo sin cultivar, y su educación con el cultivo de ese campo. Esta metáfora dio pie a hablar del cultivo del alma o cultivo de las aptitudes propias del ser humano. En este sentido hablar de un ser cultivado nos lleva a pensar en alguien que ha sido instruido o educado, en una persona culta.

Un segundo significado, que se ha trasmitido desde el siglo XVIII el concepto de cultura viene a significar también, sobre todo a partir de la Ilustración, el fruto de esa formación y perfeccionamiento del hombre: designa el conjunto de costumbres, instituciones, conocimientos, técnicas, prácticas religiosas y valores éticos propios de una sociedad o de un periodo histórico determinado.

Por eso, si hablamos de multiculturalidad es porque, de hecho, constituye un desafío serio y consciente para facilitar una mayor integración social y política en nuestras sociedades. Frecuentemente, el rechazado rápido y violento de personas diferentes a nosotros es una respuesta demasiado común, pero sumamente peligrosa. Indudablemente, la convivencia social y política de distintas culturas y personas en una

${ }^{46}$ Vid. Pacto Internacional de los Derechos Civiles y Politicos aprobado por la Asamblea General de Naciones Unidas el 16 de Diciembre de 1966. Véase CARRIÓN RODRÍGUEZ, Alejandro J., «El derecho internacional a la hora de la globalización» en OLIET PALÁ (comp.) Globalización, Estado y Democracia, Servicio publicaciones Universidad de Málaga, Málaga, 2003; CARRILLO, Salcedo, J. A., «Dignidad frente a barbarie» en La declaración Universal de los Derechos Humanos cincuenta años después, Trotta, Madrid, 1999.

${ }^{47}$ Cfr. CLIFFORD, Geertz, Tras los hechos. Dos paisajes, cuatro décadas y un antropólogo, Paidós, Barcelona, 1996. 
sociedad no es algo fácil. En muchas ocasiones, nos dirigimos hacia todo lo opuesto a la "sociedad abierta» ${ }^{48}$, que en su momento predicó Popper, como antídoto de las sociedades comunistas y totalitarias. La sociedad abierta, plural y democrática no ha sabido reconocer pacíficamente a todo el mundo. Paradójicamente, los países más desarrollados, allí donde la democracia moderna se ha consolidado con mayor solidez -Estados Unidos y Europa- son enormemente sensibles a este tipo de movimientos intolerantes o fundamentalistas pues la problemática de integración es fundamental y decisiva para preservar sus modelos de vida. El caso es que la intolerancia no va solo del poderoso al débil, sino que se hace recíproca entre las comunidades culturales que conviven entre sí. Pensemos en el ejemplo EEUU, país eminentemente multicultural que sigue teniendo pendiente la asignatura de una verdadera política intercultural o integración de minorías étnicas, raciales y culturales, junto al reconocimiento de su ciudadanía.

El liberalismo político realiza una defensa radical de las libertades individuales ante la intromisión o injerencia ilegítima del Estado. El liberalismo como teoría política posibilita un marco político y jurídico de respeto y reconocimiento amplio de los derechos fundamentales de todos los ciudadanos en un Estado democrático. Un valor fundamental del liberalismo es el pluralismo ideológico, político, religioso y cultural. En este aspecto, el liberalismo político constituye un código moral, político y jurídico sumamente eficaz donde asentar los cimientos para desarrollar una sociedad intercultural y multicultural ${ }^{49}$.

El problema fundamental hoy es que «la cultura, los valores culturales sin más, no se miden de hecho, desde patrones éticos, sino desde cánones de la cultura de $\operatorname{masas}^{50}$, como es la cultura

${ }^{48}$ POPPER, K. R., The Open Society and its Enemies. Lodres Roithledge and Kega Paul, 1945; POPPER, K. O., En busca de un mundo mejor, Barcelona, Piados, 1994.

${ }^{49} \mathrm{Vid}$. GIOVANNIi SARTORI insiste que aunque tolerancia y pluralismo son conceptos diferentes están fuertemente imbricados porque el segundo necesariamente presupone el primero. SARTORI, Giovanni, La sociedad multiétnica. Pluralismo, multiculturalismo y extranjeros, Madrid, Taurus, 2001; LUQUE, Enrique, Antropología política. Ensayos críticos. Barcelona, Ariel, 1996.

${ }^{50}$ El afán imperialista de absorber culturas menores o minoritarias existe y ha existido. Pero hoy nos hallamos ante otro fenómeno cuyo alcance minimiza los posibles efectos del primero. La cultura moderna se ha hecho cultura de masas. Y la masificación -tan denostada hace ya un siglo por STUART MILL, SIMMEL u ORTEGA Y GASSET- es menos mala si no acaba por engullirlo todo en sus patrones. Conviene, pues, ver cuáles son los peligros fundamentales de la cultura de masas a fin de salvar no sólo las diversidades, sino la cultura como tal, de su tendencia a engullirlo todo. Véase STUART MILL, J. Sobre la libertad, Madrid, Alianza Editorial, 1985 , p. 85 . 
de los países ricos, industrializados y desarrollados, orientados al crecimiento. Nuestros universales no son los de la ética.» ${ }^{51}$ El problema ético y jurídico de la diversidad cultural ha de ser confrontado con la tesis de la homogeneidad cultural, una cultura cada vez más compartida por todos, ante la cual es preciso analizar el proceso de homogeneización cultural en el que estamos inmersos.

\section{CONCLUSIONES}

La nuevas política multicultural pretenden resolver problemas que atañen al pleno reconocimiento de la ciudadanía multicultural (inmigrantes, indígenas o nacionales minoritarias). Estos nuevos grupos étnicos y nacionales se sitúan en el centro de la escena política y requieren ser abordados desde principios liberales de igualdad, pero también desde políticas diferenciales dadas peculiaridades y características concretas. El problema del reconocimiento de las minorías nacionales es agudo y complejo, porque nos sitúa en la interpretación de cómo entender el derecho a la autodeterminación política en el seno de un Estado democrático ya conformado. La experiencia historia reciente nos demuestra que los odios ancestrales y la intolerancia fomentan y constituyen un caldo de cultivo para ciertas minorías nacionales que entienden este derecho como un derecho absoluto e ilimitado, y pueden llevarnos la segregación racial, depuración étnica y genocidio como los que se han cometido recientemente en la ex Yugoslavia y Ruanda. Los derechos de estas minorías étnicas o nacionales no proporcionan potestad para que unos grupos sociales dominante a los demás grupos. En este sentido, se precisan restricciones y límites a estos derechos de minorías para que se asegure la igualdad plena entre todos los individuos por igual, independientemente de su origen étnico, racial o nacional. El liberalismo político observa estos nuevos derechos colectivos bajo esta perspectiva; pero debemos avanzar hacia un pleno reconocimiento también de sus peculiaridades.

La democracia no es un simple juego de triunfo de mayorías sobre minorías. En todo Estado democrático, que se reconozca como tal, los derechos individuales ciudadanos y los derechos de

${ }^{51}$ CAMPS, Victoria, «El derecho a la diferencia» en OLIVÉ León, Ética y diversidad cultural, México, F. C. E., 2002. Vid. VILLORO, L., Estado plural. Diversidad de culturas, México, Paidós, 1998; Escámez Navas, Sebastián, «La razón ocultó la cara del pluralismo del pensar político» en VOLUBILIS (Revista de pensamiento U.N.E.D.), n. ${ }^{\circ} 12$, pp. 90-102. 
las minorías deben ser respetados. El constitucionalismo multicultural constituye una asignatura pendiente todavía en muchos países. Los conflictos étnicos entre ciudadanos de un mismo Estado o país ponen de relieve que el modelo de ciudadanía liberal y nacional no ha resuelto muchas de los dilemas, aporías y conflictos que nos presenta el multiculturalismo global. Por otro lado, el multiculturalismo ha puesto en evidencia como la supuesta neutralidad cultural del Estado liberal y democrático es falsa, pues el Estado contemporáneo defiende patrones de una determinada cultura societal.

La posición intercultural trata de profundizar en un modelo de diálogo, espacio y encuentro hacia una mayor comprensión y entendimiento posible del problema multicultural que surge de las actuales migraciones globales, el reconocimiento de poblaciones indígenas o nativas históricas, y el reconocimiento de ciertos niveles de autogobierno de minorías nacionales. El modelo intercultural trata de conciliar un marco legítimo mínimo de derechos fundamentales con el reconocimiento explícito de las diferencias culturales de un determinado individuo o grupo étnico. Desde esta perspectiva, considero imprescindible ir atisbando y dilucidando un nuevo modelo de ciudadanía multicultural que vaya relativizando y eliminado, por un lado, los viejos nacionalismos decimonónicos excluyentes y, por otro lado, ciertos separatismos comunitaristas hacia nuevas formas de integración social, política y jurídica. La posición intercultural requiere de un enorme esfuerzo de comunicación, diálogo, comprensión y encuentro. El diálogo no es una posición de debilidad y claudicación, sino de fuerza, prestancia y creatividad. Dentro de esta comprensión de un auténtico encuentro intercultural que rescate la verdadera «riqueza humana» es necesario tomar conciencia de los contenidos de nuestras propias tradiciones, un encuentro profundo y sincero que descubra y desarrolle la común humanidad que todos llevamos dentro hacia la construcción de una ciudadanía democrática mundial o trasnacional. En este sentido, voy a tratar de desarrollar varios modelos de ciudadanía multicultural que considero promueven un verdadera integración efectiva desde la construcción de un auténtico diálogo intercultural.

En oposición al relativismo cultural o a ciertas tendencias políticas del multiculturalismo o comunitarismo, debemos superar la visión de pensar que porque no existen fundamentos absolutos sobre nuestros valores estos no son válidos para nuestra forma de actuar. En este sentido, es necesario asumir en nuestras sociedades 
un núcleo básico de valores que aparezcan como irrenunciables, precisos y orientadores. Sólo si profundizamos en esta línea de concreción política-jurídica de nuevas instituciones constitucionales podremos desarrollar modelos de ciudadanía multicultural y un Estado federal que respete y reconozca los derechos culturales como derechos diferenciales desde una concepción integradora y armónica. 